Das Manihot-Öl kann man in die Klasse der trocknenden Öle einreihen. Es ergab bei der Probe nach Livache nach achttägigem Stehen eine Gewichtszunahme von $7,69 \%$. Beim Bromieren in ätherischer Lösung wurde ein Niederschlag von Hexabromglyceriden nicht erhalten.

Die Fettsäuren waren in festem Zustande von hellgelber Farbe, in geschmolzenem von goldgelber Farbe. Beim Bromieren nach der Methode von Farnsteiner wurde eine grobe Menge von in kaltem Petroläther unlöslichem Rohbromid erhalten, dessen Schmelzpunkt bei $115^{0} \mathrm{lag}$; es löste sich vollständig beim Auskochen mit Äther. Es dürfte somit nur aus Linolsäuretetrabromid besteben, dem vielleicht Spuren von Linolensäurehexabromid beigemengt waren. Nach Fendler und $\mathrm{Kuhn}$ bestehen die Fettsäuren zu 10,97\% aus festen (Schmelzpunkt: 54\%) und zu 89,03\% aus flüssigen Fettsäuren (Jodzahl: 163,6); Rideal und Acland fanden 88,9\% flüssige Fettsäuren mit einer Jodzahl von 162,5.

Mit dem Bellier'schen Reagens auf Pflanzenöle ergab das Manihot-Öl eine tiefblaue Färbung.

Wegen seiner trocknenden Eigenschaften ist das Manihot-Öl technisch für die Firnisfabrikation brauchbar. Nach Rideal und Acland trocknet es ziemlich schnell ein, wobei eine zähe, elastische und hellfarbige Haut resultiert. Als spezifisches Merkmal geben diese Autoren ferner an, daß unraffiniertes Öl beim Erhitzen mit Manganresinat $(1-2 \%)$ eine schöne Rosafärbung hervorruft.

Der Ceara-Kautschukbaum ist beimisch in der Provinz Ceara, ist aber von dort nach fast allen Tropenländern der alten Welt überführt und mit gutem Erfolge angepflanzt worden. Für Zwecke der Kautschukgewinnung ist er namentlich auf einer großen Anzahl Plantagen in Deutsch-Ost-Afrika angebaut.

\title{
Untersuchungen fettreicher Früchte und Samen unserer Kolonien.
}

\author{
„Mabula Pansa“. \\ Von
}

\section{H. Wagner und J. Muesmann.}

Mitteilung aus dem Staatlichen Chemischen Untersuchungs-Amte für die Auslandsfleischbeschau zu Duisburg.

Die deutschen Kolonien besitzen eine grobe Anzahl Pflanzen, deren Samen bezw. Früchte sehr reich an Fett sind; sie dürften ihres Fettgehaltes wegen für die deutsche Fettindustrie noch von Wichtigkeit werden. Über die Zusammensetzung und Art dieser Fette ist verhältnismäßig wenig bekannt geworden. Gearbeitet haben hierüber u. a. Fickende $\mathrm{y}^{1}$ ), $\mathrm{Krause}^{2}$ ), K. Wedemeyer ${ }^{3}$ ) und vor allem Cl. Grimmes), der eine große Anzahl seltener und zum Teil unbekannter- Früchte

1) Tropenplanzer 1910, 29 usw.

2) Chem. Revne ü. d. Fett- u. Harz-Industrie 1907, 2, 35 usw.

3) Tropenpflanzer 1909, 281; 1910, 258 usw.

4) Tropenpflanzer 1910, 297; Chem. Revue ü. d. Fett- u. Harz-Industrie 1912, 17, 157 bis 158 usw. 
und Samen bezw. deren Fett auf ihre chemische Zusammensetzung hin untersuchte. Wir haben es auch unsererseits unternonımen, derartig weniger bekannte Samen und Früchte des näheren zu untersuchen; durch Vermittelung des Reichskolonialamtes haben wir aus den verschiedensten deutschen Kolonien reiches Untersuchungsmaterial erhalten. Bis jetzt sind uns übermittelt bezw. in Aussicht gestellt worden:

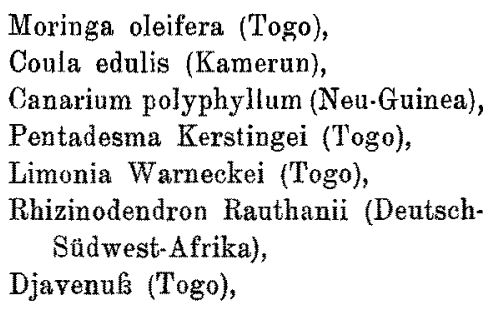

Mankettinuk (Togo),

Aluwitis molucana (Samoa),

Plakenetia canophora (Kamerun),

Butyrospermum Parkei (Kamerun und Togo)

Ölfrüchte: Sede, Ede, Afade, Dedugbakui, Klode (Togo).

Als ersten Samen untersuchten wir Mabula Pansa, den wir teils vom Reichskolonialamte, teils von dem bekannten Afrikahause Wörmann in Hamburg zur Verfügung gestellt bekamen. Von dieser Firma erbielten wir folgende Angaben:

„Mabula Pansa stammt von meiner Niederlassung in Landana (Westafrika). Diese Frucht (Owalasamen oder Pauconüsse von Pentaclethra macrophylla) besteht zu $21,4 \%$ aus Schale und zu $78,6 \%$ aus Kern mit $36,5 \%$ Öl. Die Verseifungszahl des Öles ist 203,0, die Jodzahl 85,7 und der Erstarrungspunkt $+20^{\circ} \mathrm{C}$. Es ist mithin von butterähnlicher Konsistenz und nicht trocknend. - Dies ohne meine Verbindlichkeit."

Die botanische Zentralstelle für die Kolonien am Kgl. Botanischen Garten und Museum zu Dahlem bei Berlin erteilte uns anf Anfrage folgende Auskunft:

„Die eingesandten Samen stammen von Pentaclethra macrophylla, einem Baum aus der Familie der Leguminosen, der im ganzen tropischen Westafrika, auch in Togo und Kamerun verbreitet ist. Besonders in den englischen und französischen Kolonien pressen die Eingeborenen ein Öl aus den Samen, das als Owalasamenöl bekannt ist. Es schmeckt zuerst süsslich, dann bitter, enthält viele Fettsäuren von hohem Schmelzpunkt, sodaß es für die Kerzenfabrikation von Wert ist."

In der uns zur Verfügung stehenden Literatur fanden wir die folgenden Angaben:

K. Wedemeyer ${ }^{1}$ ) „Über das Owala.Öl“: Die Owalasamen stammen von der Westküste Afrikas und haben die Form einer flachen Teichmuschel. Aus einem Kilo Samen ergeben sich im Durchschnitt 20,6\% Schalen, 79,4\% Fleisch. In dem Samen mit Schale waren vorhanden $30,4 \%$ Öl, mit Äthyläther extrahiert, und $39,3 \%$ Protein. In dem extrahierten Öle waren $3,63 \%$ freie Säure vorhanden, berechnet auf das mittlere Molekulargewicht der Fettsäuren des Owalaöles. Das extrahierte Öl war sehwach gelblich, bei Zimmertemperatur flüssig, mit geringen Ansscheidungen, klar löslich in den bekannten Lösungsmitteln. Der Geschmack war angesehm, hinterher kratzend, der Geruch aromalisch, durch Raffination ließs sich ein feines, als Speiseöl brauchbares Öl darstellen, spez. Gewicht des Rohöles bei $25^{\circ} \mathrm{C}$ $=0,9119$; bei Abkühlung anf $18-19^{\circ} \mathrm{C}$ fanden bereits weibe, floekige Ausscheidungen statt, bei $14^{\circ}$ wurde das Öl butterartig fest, sodaß dasselbe sich nicht mehr gießen liek; bei $+8^{\circ} \mathrm{C}$ ging die butterartige Masse in einen festen Brei über.

An Konstanten werden angegeben:

1) Chem. ì. d. Revue, Fett- und Harz-Industrie 1906, 13, 210-211; diese Zeitschrift 1907, 14, 539 . 
Hohner'sche Zahl . . . . . . . 95,6|Säurezahl . . . . . . . . . . 9,0

Reichert-Meisl'sche Zahl . . . 0,6 Unverseifbares . . . . . . . . $0,54 \%$

Verseifungszahl . . . . . . . 186,0

Jodzahl . . . . . . . . . . . . 99,3

Thermische Probe (Maumené) . . . 100,0

Refraktometerzahl (bei $40^{\circ}$ ) . . . 59,2

Acetylzahl . . . . . . . . . . 37,1

Fettsäuren des Öles:

Eine weitere Angabe besagt folgendes ${ }^{1}$ ):

Das untersuchte Produkt bestand aus groken, flachen, mit einer harten, braunen Schale versehenen Samen. Sie waren 1,5-2,7 engl. Zoll lang, 1,2-1,8 engl. Zoll breit und $0,3-0,4$ Zoll dick. Die frischen Kerne der Bohnen sind weich und weiß; von den zur Untersuchung gelangten war ein Teil bereits verdorben. Bei den Bohnen machen die harte Schale 20,7\% ans und die Kerne 79,3\%; der Gesamtölgehalt der Bohnen beträgt $31,2 \%$, der Ölgehalt der Kerne (d. h. Bohnen, von der harten Samensehale befreit) $39 \%$. Es wurde das durch Extraktion aus einer Durchschnittsprobe erhaltene Öl sowie das aus unversehrten Samen nntersucht.

\begin{tabular}{|c|c|c|}
\hline Bestimmung & $\begin{array}{l}\text { Durchschnittsprobe } \\
\text { des Ôles }\end{array}$ & Öl aus unversehrten Samen \\
\hline 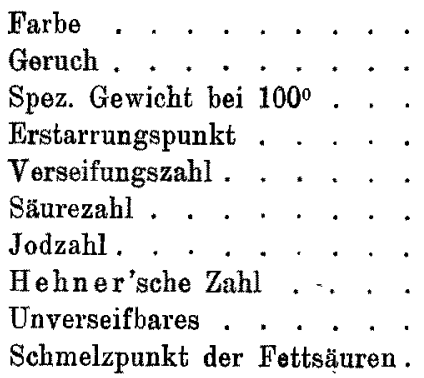 & $\begin{array}{c}\text { gelblichbraun } \\
\text { stechend } \\
0,8627 \\
+\mathbf{5}^{0} \mathrm{C} \\
\mathbf{1 8 2} \\
10,0 \\
94,4 \\
95,7 \\
0,27^{\circ} \% \\
53,4^{\circ} \mathrm{C}\end{array}$ & $\begin{array}{c}\text { hellgelb } \\
\text { etwas stechend } \\
0,8637 \\
+8^{0} \mathrm{C} \\
185 \\
4,6 \\
94,3 \\
94,2 \\
-{ }_{52}^{0} \mathrm{C}\end{array}$ \\
\hline
\end{tabular}

Das Öl gehört za den nicht trocknenden Ölen. Der stechende Geruch kann durch die gewöhnlichen Raffinationsmethoden nicht entfernt werden. Bei dem Versuch, die Bohnen zur Seifenfabrikation $z u$ verwenden, stellten sich verschiedene Schwierigkeiten heraus, insbesondere mukten die Bohnen erst geschält werden, um nicht den braunen Farbstoff der Schale mitznbekommen. Nach einem von einer technischen Stelle abgegebenen Gutachten ist eine aus dem Öle hergestellte Seife schlecht und minderwertiger als Cottonölseife. Trotz des hohen Schmelzpunktes der Fettsäuron liefert das Öl eine ziemlich weiche Seife. Der beim Extrahieren des Öles gewonnene Kuchen besak folgende Bestandteile:

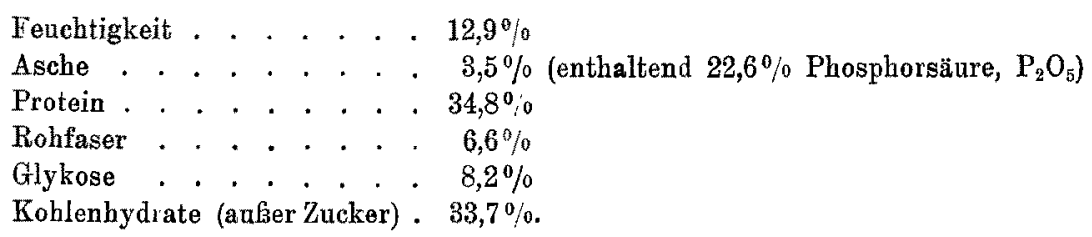

Hiernach besitzt das Mehl einen hohen Nährwert."

Cl. Grimme ${ }^{2}$ ) macht nähere Angaben über die botanischen Eigenschaften der Pflanze, die hier angefübrt seien, da wir trotz unserer Bemühungen, darüber mehr zu erfahren, keinen Erfolg hatten.

1) Ölbohnen von Südnigeria (Owala-Bohnen) - Oil and Trades Journ. 31, No. 447/48; Chem. Rev. Fett- and Harz-Industrie 1907, 14, 218-220; diese Zeitschrift 1908, 15, 629.

2) Chem. Revue über die Fett- und Harz-Industrie 1910, 17, 157-158. 
„Pentaclethra macrophylla, zur Familie der Leguminosen gebörend, ist ein mächtiger Baum der eigentlich an der ganzen Westküste Afrikas vorkommt. So findet er sich in Senegambien (Casamance), im Bayotteland (Kandiola und Candi), in Rio Nunez, Fernando Po, Kamerun, auf den Prinzeninseln, auf St. Thomas, in Französisch-Guinea, an der Elfenbeinküste und vielen anderen Plätzen. Yon den vielen Eingeborenennamen, die naturgemäGe Folge seines verbreiteten Vorkommens, seien nur einige erwähnt: Owala (Gabun), Opachala (Sousouland), Panza (Kongo) und Nulla Panza (Angola).

Der Baum, der gewaltige Dimensionen erreicht, hat doppelt gefiederte Blätter, seine Blütezeit ist im Juli und August. Die Bläten sind weißlich gelb und stehen in verlängerten rispig angeordneten Ähren. Die Fruchtreife ist im Dezember. Die Frucht ist eine mächtige Hülse, schief, am Grunde verschmälert, Hach zusammengedrückt und besteht aus 2 lederartigholzigen Klappen, die sich beim Aufspringen elastisch zurückrollen und so die 6-7 großen Samen weit fortschleudern. Die Samen sind 7-8 cm lang, etwa $5 \mathrm{~cm}$ breit, kastanienbraun, plattgedrückt, oval und an ibrer Anheftungsstelle zugespitzt. Im Durchschnitt wiegen sie $15-20 \mathrm{~g}$. Die Samenschale ist lederig und zeigt wenig hervortretende, grofmaschige Netzadern. Die olivengrünen Samenlappen werden von den Eingeborenen gegessen. ${ }^{\text {t }}$

Die von Grimme bestimmten Werte weichen von den vorher angeführten mehrfach ab; er fand:

„A. Samen: $21,4 \%$ Schale; $78,6 \%$ Endosperm oder Kern, in diesem $36,5 \%$ Öl, auf ganzen Samen berechnet $28,72 \%$.

\section{B. Fett:}

Spez. Gewicht bei $15^{0}$. . . . . 0,9259

Erstarrungspunkt: bei $20^{\circ} \mathrm{C}$ butterartig; bei $5-7^{0} \mathrm{C}$ fest.

Brechungsindex . . . . . 1,4728 $\left(30^{\circ}\right)$

Säurezahl . . . . . . . . . . 9,2

Verseifungszahl . . . . . . . . 203,0

Jodzahl .. . . . . . . . . . 85,7

Unverseifbares . . . . . . $3,17 \%$

Der Extraktionsrückstand enthält 52,21\% Protein."
Fettsaruren:

Hehner'sche Zahl . . . . 9 91,85

Schmelzpunkt . . . . . . . . $58-59^{\circ}$

Brechungsindex . . . . . . . 1,4647

Sättigungszahl . . . . . . . . 192,7

Jodzahl . . . . . . . . . . 92,6

Mittleres Molekular-Gewicht . . 291,5

Im weiteren werden wir unsere Befunde gegenüberstellen. Die Samen sind von flachnierenförmigem, teils muschelähnlichem Aussehen, dunkelbraun, von glatter, schwachgefurchter Oberfläche.

Wie aus den Abbildungen (S. 128) zu erkennen ist, besitzen die Samen nur eine dünne, dunkelbraune Schale. Der Kern besteht aus den sehr großen, flachen Keimblättern, in welchen alle Nährstoffe aufgespeichert sind; die Farbe der Kerne ist im frischen gesunden Zustande gelblich, im älteren oder kranken braun bis schwarz. Die Kerne scheinen von tierischen und pflanzlichen Parasiten stark heimgesucht zu werden. Von den uns übersandten Samen waren etwa $83 \%$ gesund und etwa $17 \%$ krank oder durch tierische Parasiten beschädigt. Im Durchschnitt wogen 100 Stück etwa $1320 \mathrm{~g}$, davon fielen auf die Kerne $1065 \mathrm{~g}=$ etwa rund $81 \%$, auf die Schalen $255 \mathrm{~g}$ oder rund $19 \%$. Die Länge der Samen schwankt zwischen $3-8 \mathrm{~cm}$, die Breite zwisehen 2,5-6 $\mathrm{cm}$ und die Dicke zwischen $0,6-2 \mathrm{~cm}$. Das Gewicht der kleinsten Samen beträgt rund $7 \mathrm{~g}$, das der größten rund $20 \mathrm{~g}$. Der Wassergehalt betrug 7,48\%, der Aschegehalt der lufttrocknen Kerne 2,23\%, mit einem Phosphorsäuregehalt von $0,45 \%$, berechnet auf Kerne. Die Schalen enthielten 4,11\% Mineralbestandteile. Der Rohfasergehalt der Samenkerne wurde nach J. König bestimmt, und zwar wurden in den vom Fett befreiten Kernen $9,39 \%$ gefunden, was auf fett- 


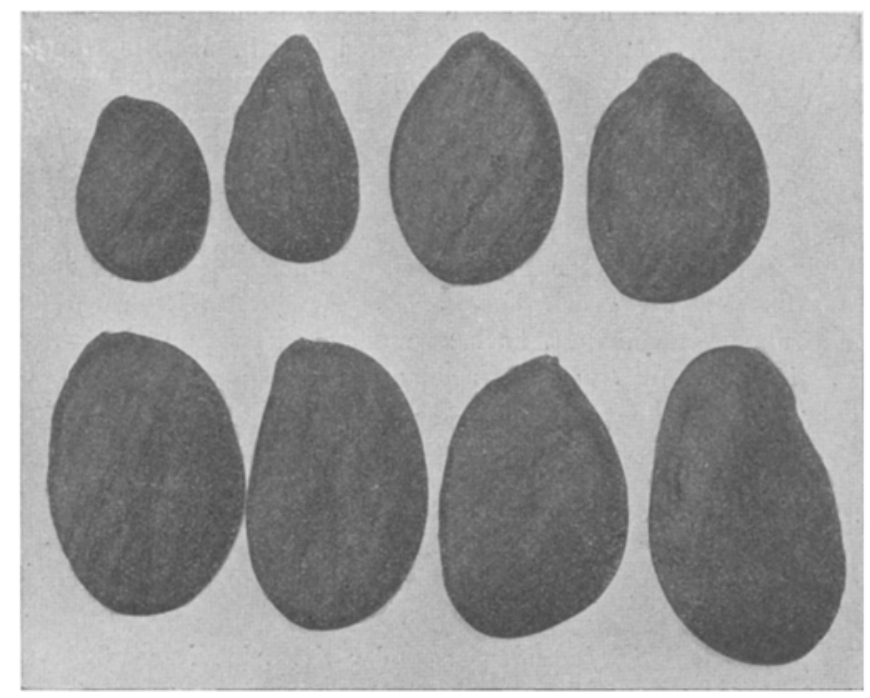

Fig 1.

Samen verschiedener Größe.

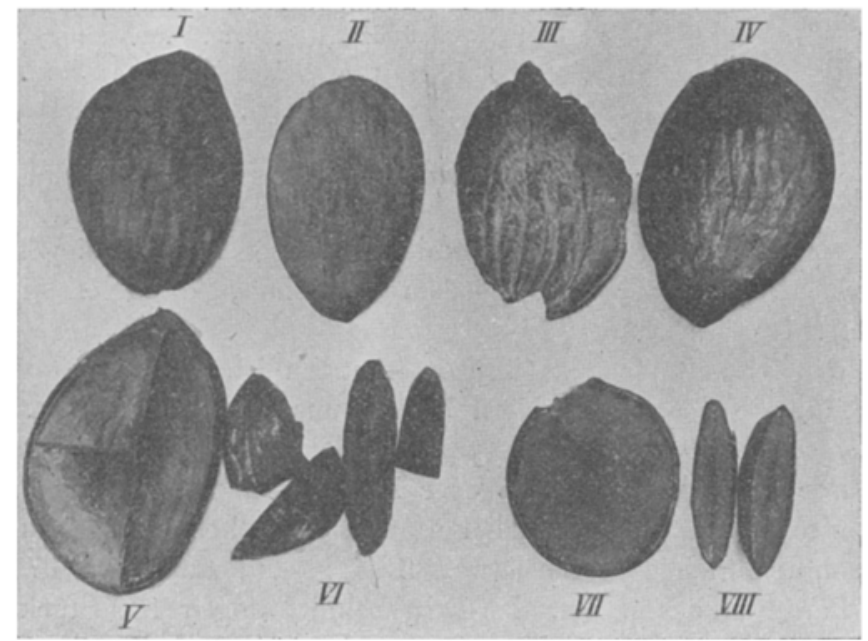

Fig. 2.

I: Dunkeler, kranker Samenkern;

II: heller, gesunder Samenkern;

III and IV: Schalen;

$V$ und VI: Kranker Samenkern im Durchschnitt;

VII und VIIl: Gesander Kern im Durchschnitt. 
haltige Samen berechnet $4,71 \%$ ergibt. Der nach $\mathrm{Kjeldahl}$ bestimmte Stickstoffgehalt ergab, auf fettfreie Substanz bezogen, $9,36 \%$, auf fetthaltige $4,68 \%$. Auf Protein berechnet, wurden also $58,5 \%$ in der fettfreien und $29,3 \%$ in der fetthaltigen Substanz gefunden. Die entfetteten Rückstände bezw. die bei einer technischen Olgewinnung zurückbleibenden Preßkuchen würden daher ein gutes Futtermittel abgeben, vorausgesetzt, då die Unschädlichkeit derselben für Tiere erwiesen würde. Der Geschmack des entfetteten Kernpulvers ist ein etwas süfilicher ohne bitteren Nachgeschmack. Wir hatten leider keine Mittel zur Verfügung, um Fütterungsversuche anstellen zu kömnen und auch das Reichskolonialamt konnte für diesen Zweck keine Unterstützung gewähren. Späterhin gedenken wir aber eine Anzahl solcher Versuche mit den Rückständen der verschiedensten Samen und Früchte gesondert anzustellen und werden dann hierauf zurückkommen.

Aus den gesunden trockenen Kernen ließen sich mittels Äthers 49,8\% Fett extrahieren, was auf die ganzen Samen bezogen 40,2\% ausmacht. Das gewonnene Ol ist bei Zimmertemperatur durch ausgeschiedene feste Fettsäureglyceride getrübt. Bei etwas höherer Temperatur wird es klar und besitzt dann eine rein gelbe Farbe. Der Geschmack war, durch viel freie Fettsäuren bedingt, ein stark kratzender, nach dem Reinigen mit Alkali ein milder mit einem geringen bitteren Nachgeschmack. Das zur chemischen Untersuchung bei $105^{\circ}$ getrocknete und filtrierte Öl ergab die in nachstehender Tabelle angeführten Werte:

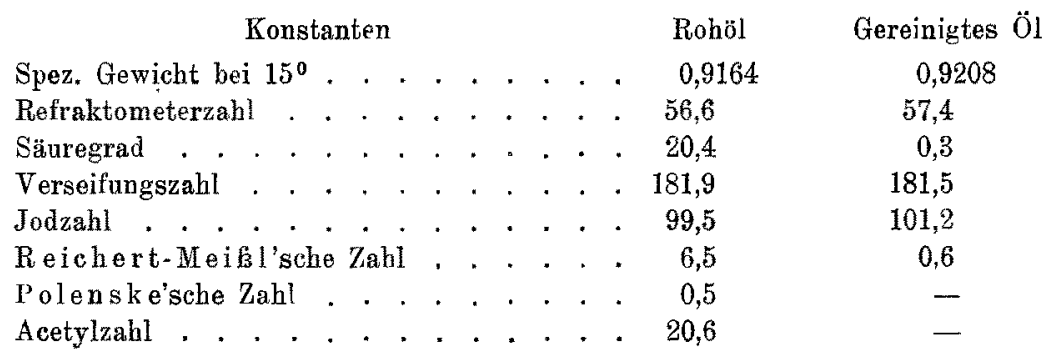

Auffallend ist bei diesen Werten die relativ hohe Reichert-MeiBl'sehe Zahl des Rohöles.

Die angestellten Farbenreaktionen nach Baudouin, Soltien und Halphen fielen negativ aus. Die Reaktion nach Bellier ergab nach 5 Sekunden eine schwarzgrüne Färbung, die bald darauf ins Rotbraune überging. Aus dem mit Brom behandelten Ölen konnte kein Hexabromid abgeschieden werden; Linolensäure dürfte also nicht vorhanden sein. Bei der Elaidinprobe wurde das Öl nach längerem Stehen fest.

Im folgenden stellen wir die bei der Untersuchung der abgeschiedenen Fet säuren ermittelten Werte zusammen:

\begin{tabular}{|c|c|c|c|c|c|c|c|c|}
\hline Schmelzpankt & $=$ & . & - & & & & & $56,5-57,5^{0}$ \\
\hline Erstarrungspunkt & & . & . & & & & & $55,2^{0}$ \\
\hline Neutralisationszahl & & & . & & . & • & & 185,7 \\
\hline Mittleres Molekularge & ewicht & . & . & & . & . & & 302,4 \\
\hline Jodzahl . . . . & & . . & & & • & . & & 106,3 \\
\hline Jodzahl der flüssigen & Fetts & ren & & & & & & $143,5-144,1$ \\
\hline
\end{tabular}

Die Refraktometerzahl wurde wegen des hohen Schmelzpunktes nicht bestimmt.

Das berechnete hohe mittlere Molekulargewicht ließ auf das Vorhandensein einer hochmolekularen Fettsäure schließen. Bei einer eingehenderen Untersuchung der ab- 
geschiedenen Fettzäuren wurde festgestellt, daß rund $25 \%$ einer festen gesättigten Fettsäure und rund $43 \%$ flüssige ungesättigte Säuren vorhanden waren, berechnet auf angewandtes 01 . Die über die Bleisalze durch mehrfaches Umkrystallisieren aus Benzol von den flüssigen gereinigte feste Fettsäure wurde noch mehrmals aus 96\%-igem Alkohol gereinigt, bis der Schmelzpunkt der aus der Mutterlange erhaltenen Krystalle gleich dem des gereinigten Produktes, war. Der konstante Schmelzpunkt der Fettsäure war $80,5-81^{\circ}$, der Erstarrungspunkt lag bei $76^{\circ}$. Die Säure krystallisiert in Schuppenform von perlmutterähnlichem Glanze und ist in Äther, Benzol, Schwefelkohlenstoff löslich; schwer in kaltem Alkohol und Petroläther, ziemlich leicht in heißem Alkohol. Die mit der Säure angesetzte Jodzahlbestimmung ergab 0,013 , ein Beweis dafür, daß die Fettsäure frei von ungesättigten Säuren war. Von dieser hochschmelzenden Säure wurden zur näheren Identifizierung verschiedene Verbindungen dargestellt, sowohl Salze wie Ester. Die Kalium- und Natriumsalze bilden in Wasser lösliche, aus Alkohol wenig krystallinisch sich abscheidende Verbindungen. Das mehrfach aus Benzol in Siedehitze umkrystallisierte Bleisalz bildet drusenförmige Konglomerate von feinen Nadeln. Es schmilat bei $117-118^{\circ}$ und erstarrt bei 113-1140. Das Silbersalz zersétzt sich beim Erhitzen und läßt daher keinen Schmelzpunkt erkennen. Es wurde erhalten durch Lösen der vollkommen reinen Säure in einer größeren Menge Alkohol, Hinzufügen von überschüssigem konzentriertem Ammoniak, um fettsaures Ammonsalz zu erhalten, und Wegdampfen des nicht benötigten Ammoniaks. Diese Lösung wird mit Silbernitratlösung versetzt und nach einiger Zeit das ausgeschiedene Silbersalz abfiltriert und auf Tonscherben getrocknet. Sowohl das Blei- wie das Silbersalz wurden auf ihren Gehalt an Metall untersucht, und zwar enthielt das Bleisalz 21,97\% Blei, das Silbersalz 22,71\% Silber.

Die Neutralisationszahl der Säure betrug 148,7, woraus sich ein mittleres Molekulargewicht von 376,7 berechnet.

Weiterhin wurden die Methyl- und Äthylester dargestellt; die Säure wurde mit dem betreffenden Alkohole und der nötigen Menge Schwefelsäure am Rückflußkühler etwa 1 Stunde erhitzt, das Reaktionsprodukt in ein mit kaltem Wasser gefülltes Becherglas gegossen, abfiltriert und bis zum gleichbleibendeu Schmelzpunkte aus Alkohol umkrystallisiert. Der Schmelzpunkt des Methylesters war $57,5^{\circ}$, sein Erstarrungspunkt 55,50; der Schmelzpunkt des Äthylesters war $55-56^{\circ}$, sein Erstarrungspunkt $53,5-54^{\circ}$. Beide Ester bilden kleine schuppenförmige, perlmutterglänzende Blättchen. Aus den gefundenen Werten konnte angenommen werden, daß es sich im vorliegenden Falle um Lignocerinsäure handeln könnte, eine hochmolekulare Säure von der Formel $\mathrm{C}_{24} \mathrm{H}_{48} \mathrm{O}_{2}$, deren Glycerid bis jetzt, soweit uns bekannt, nur in geringerer Menge im Arachisöl gefunden worden ist. Ausgeführte Elementar-Analysen bestätigen diese Annahme.

$0,2082 \mathrm{~g}$ angewandte Säure gaben bei der Verbrennung $0,5962 \mathrm{~g}$ Kohlensäure und $0,2476 \mathrm{~g}$ Wasser.

Bei der Verbrennung des Äthylesters $\mathrm{C}_{24} \mathrm{H}_{47} \mathrm{O}_{2} \cdot \mathrm{O}_{2} \mathrm{H}_{5}$ wurden aus $0,2346 \mathrm{~g}$ Substanz 0,6794 Kohlensäure und 0,2694 g Wasser erhalten.

Zur besseren Übersicht seien die berechneten und die gefundenen Werte einander gegenübergestellt: 
Bestimmung: Berechnet Gefunden

\begin{tabular}{|c|c|c|c|c|c|}
\hline Neutraligationszahl. & & & & 152,3 & 148,2 \\
\hline Mittleres Molekulargewicht & & & & 368,4 & 376,7 \\
\hline Blei im Bleisalz. . . . & . & & " & $21,97 \%$ & $21,50 \%$ \\
\hline Silber im Silbersalz . & & & & 22,71, & 22,47 \\
\hline Kohlenstoff in der Sänre & * & & & 78,18 & 78,10 \\
\hline Wasserstoff in der Säure & & & & 13,13, & 13,31 \\
\hline Kohlenstoff im Äthylester & & & & 78,70 & 78,98 \\
\hline Wasserstoff im Äthylester & & & & 13,25, & 12,85 \\
\hline
\end{tabular}

Lewkowitseb ${ }^{1}$ ) gibt für Lignocerinsäure und ihre Ester folgende Werte an, denen die von uns gefundenen nochmals beigefügt sind.

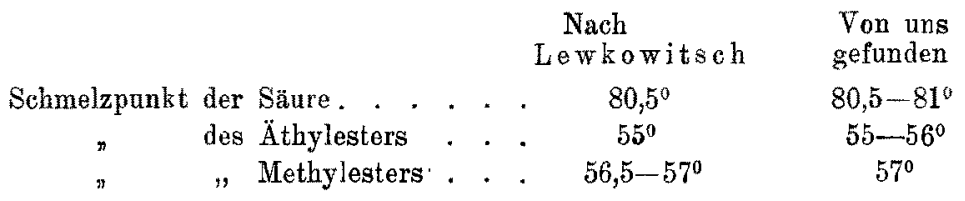

Die gefundenen Werte stimmen also mit den berechneten und bereits früher festgestellten soweit überein, daß die in Frage stehende Säure als Lignocerinsäure angesprochen werden darf.

Die Menge der in dem Fett von Mabula Pansa enthaltenen unverseifbaren ätherlöslichen Bestandteile wurde nach A. Bömer bestimmt und als Rohphytosterin gewogen $=0,62 \%$. Reinphytosterin vom Schmelzpunkt $140,8^{\circ}$ wurden $0,21 \%$ gewonnen, dessen Acetat den Schmelzpunkt 132,4 $4^{0}$ zeigte.

Zum Schlusse sei der Verwendungsmöglichkeit gedacht. Da das Fett in den Herkunftsländern von den Eingeborenen als Nahrungsmittel benutzt wird, so dürfte kein Grund vorliegen, es aus unserer Nahrungsmittelindustrie fern zu halten. Den etwas bitteren Nachgeschmack des nur in kleinem Maße im Laboratorium gereinigten Öles zu entfernen, dürfte der heutigen Fettindustrie kaum schwer fallen. Aufklärung müßte auch noch über die Verdaulichkeit des Fettes gebracht.werden, wie überbaupt Versuche mit derartigen Fetten stets in der Praxis gemacht werden sollten. Wenn, wie durch Versuche festgestellt worden sein soll, das Fett sich nicht zur Seifenfabrikation eignet, so wäre vielleicht wegen des hohen Schmelzpunktes der Fettsäuren eine Verwendung in der Kerzenindustrie möglich, falls sich die Gewinnungskosten und Frachten nicht zu hoch stellen werden.

1) Lewkowitsch, Chemische Technologie u. Analyse der Fette, Öle u. Wachse $1905,1,105$. 